\title{
IOT-Based Smart Lamp Using Arduino
}

\author{
Diviandi Muhammad, Ghalib Eko Prasetyo, Muhammad Ferrizal Ramadhan, Antonius Suhartomo \\ Department of Electrical Engineering, President University, Bekasi 17550, Indonesia \\ Email: diviandimuhammad@gmail.com,ghalib12223@gmail.com, ferriza199@gmail.com, asuharto@president.ac.id \\ Corresponding author: diviandimuhammad@gmail.com
}

\begin{abstract}
This project is the application of IoT for home appliances, in particular lighting. The prototype is making use NodeMcu as the main controller and free to use IoT platform BLYNK. The combination of these two provides capabilities to control the lamp(s) remotely using smartphone connected to the Internet. The prototype uses Google Assistant to turn on and turn off the lamp remotely using voice command.
\end{abstract}

Keywords: IoT, NodeMCU, Google Assistant, Lamp, remote, BLYNK.

\section{Introduction}

IoT is the use of technology in the future that uses the internet network to develop existing technology to make it easier to use and has many functions. In the future every home will use IoT technology to make it more comfortable to live in. So, with the internet we make "Smart Lamp" based on IoT for operating lights at home.

Smart Lamp is an amalgamation of relay and NodeMcu for the use of lights at home. In its use the lamp will be able to operate using mobile phones and the internet via the google assistance command. Through google assistance we can command the lamp by saying "Hello Google, turn on the lamp" then google will give the answer "OK boss" coupled with the lights on Then to turn off the lights we say "Hello Google, Turn off the lamp" then google will answer "Good night, Have a nice dream" coupled with the lights go oult. Our tools can help people's desires to be able to monitor the use of electricity the use of lamps becomes easier.

\section{Basic Theory}

\section{A. NodeMCU}

In this project we use NodeMCU. NodeMCU is an open-source IoT platform that uses the ESP8266 chip and uses the Lua scripting programming language. Basically, NodeMCU is a microcontroller that is added to the LX106 Wi-Fi module which is combined into a compact form, which in its use can be control with mobile phones through the internet network.

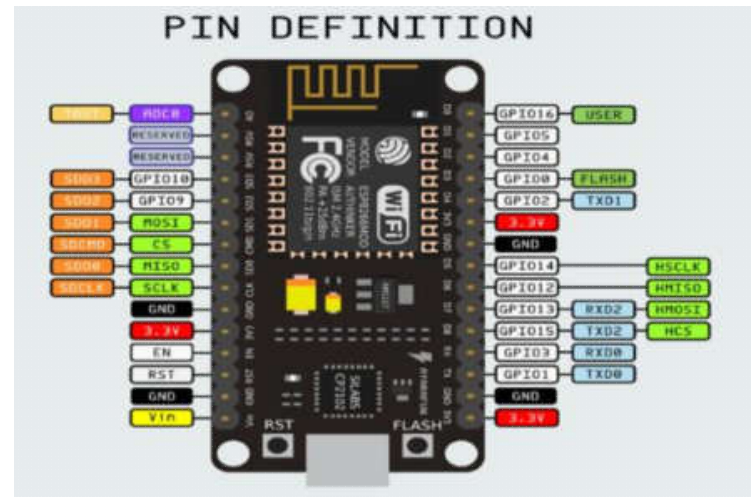

Figure 1. NodeMCU Pin Definition.

As can be seen in Figure 1, some main features of NodeMCU

1. 10 Port GPIO form D0 - D10

2. PWM Function

3. Interface $\mathrm{I} 2 \mathrm{C} \& \mathrm{SPI}$

4. $\mathrm{ADC}$

The use of NodeMCU and Arduino is very similar, but the NodeMCU already has several features already integrated on the board such as the $\mathrm{Wi}-\mathrm{Fi}$ feature where when using Arduino we have to add a Wi-Fi module where it is not easy and troublesome because we have to install the cable and port Wi-Fi module on Arduino but the NodeMCU feature is already installed and we just use it.

\section{B. Relay}

Relays can be used to connect and disconnect the currents according to what we want. Relays can also be used as timers to perform tasks in turn. This can be done because the relay has NO (Normally Open) and NC (Normally Close) ports that can be controlled by a microcontroller and then developed to be many things. Basic construction of relay can be seen in Figure 2. 

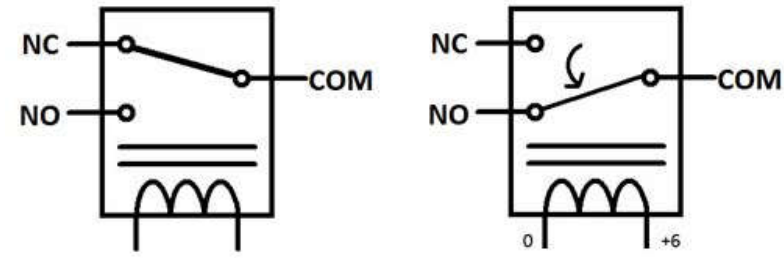

Figure 2. Construction of relays

The operations of relay is as follows; when the coil is given a voltage, the coil position will be $\mathrm{NC}$ which makes the current pass through the relay but when the coil does not get the voltage the coil position will be NO so that no current can pass through the relay and you can choose what position you want to use.

Pin connections for relay for $\mathrm{AC}$ and $\mathrm{DC}$ circuit is shown in Table 1.

Table 1. Pins for Relay

\begin{tabular}{|l|l|}
\hline AC & DC \\
\hline $\begin{array}{l}\text { COMM (common pin for source of } \\
\text { voltage) }\end{array}$ & GND \\
\hline PIN NO (Normally Open) & VCC(3.3 volt) \\
\hline PIN NC (Normally Close) & IN (data from microcontroller) \\
\hline
\end{tabular}

\section{LED Lamp}

In this project we use LED lights with voltage $220 \mathrm{~V}$ and 12 watts. The use of LED lights is so that the electricity used is lower and more efficient then in longterm use is more durable. Led lights are also not hot so it is safer when errors occur in. An example of LED lamp is shown in Figure 3.

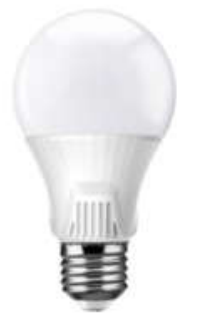

Figure 3 LED Lamp.

\section{System Design}

\section{A. Hardware Implementation}

The Prototype design for this project can be seen in Figure 4.

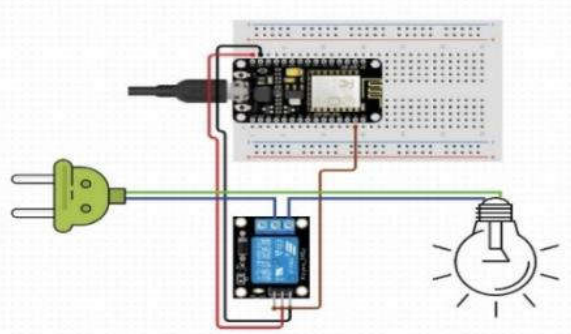

Figure 4. System Design.
The system workflow can be seen in Figure 5.

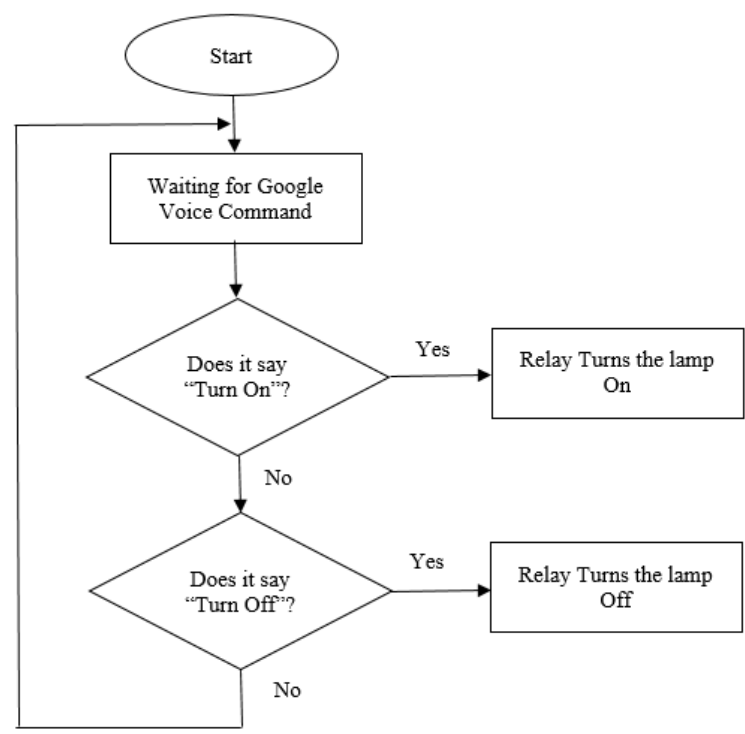

Figure 5. System Flow Chart.

\section{B. Software Implementation}

Besides the hardware that we use, there are some software application like IFTTT (If This Then That) and BLYNK.

Actually, there are many applications that we use to help us to work, but for the IFTTT and BLYNK are the core.

\section{IFTTT}

IFTTT is a software or we can say web-based services that help us to create chains of simple conditional statements that called applets. The benefits that really help us because it's free and easy to access, so for us that want to try will not make any difficulties. It provides so many connections to some webs and applications services, that will not make limitation to our creativity. In this module of projects, we make connection to webhooks.

This platform also provides Goggle Assistant option to trigger a pre-defined event such as turning on and off the lamp. An example of such configuration is shown in Figure 6.

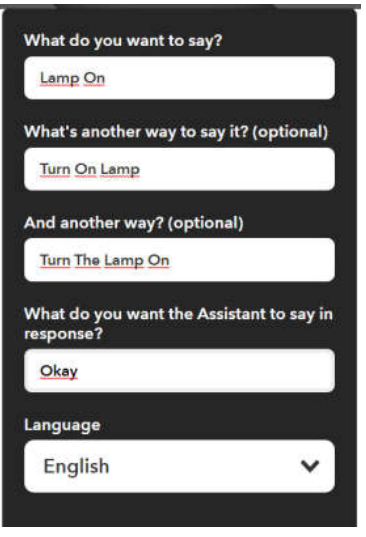

(a)

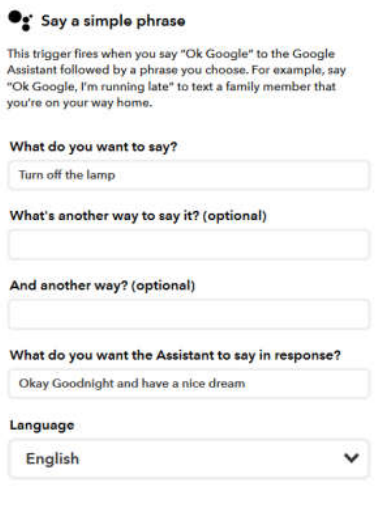

(b)
Figure 6. IFTTT Setup for (a) turning on the lamp and (b) turning off the lamp. 


\section{BLYNK}

BLYNK (see Figure 7) is another application that we use, that the use is in our mobile phone that so easily we find. It can be found in playstore for android user and iOS for iPhone. BLYNK is one of the applications of IoT, that connects module to internet so easily. Another benefits that given is we can make diagnostic by private clouds, giving data analytics, and machine learning. It also can connect us to many applications and webs.

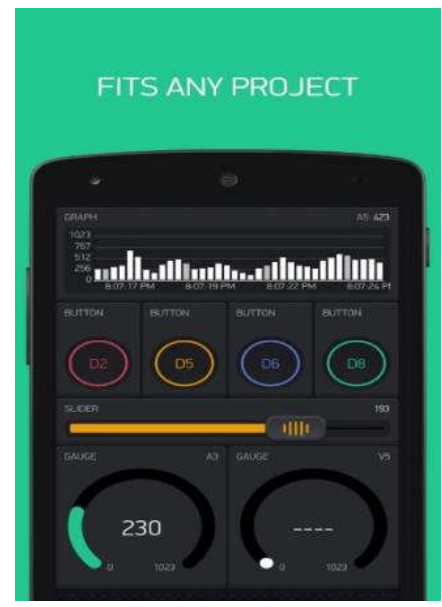

Figure 7. Front view of BLYNK application.

\section{Microcontroller Code}

Besides the web-side of software, the microcontroller also needs to be set up to connect properly to BLYNK. The code for NodeMCU is using the same language as Arduino. An example of script connecting NodeMCU to BLYNK is shown in Table 2.

\section{Table 2. NodeMCU Code}

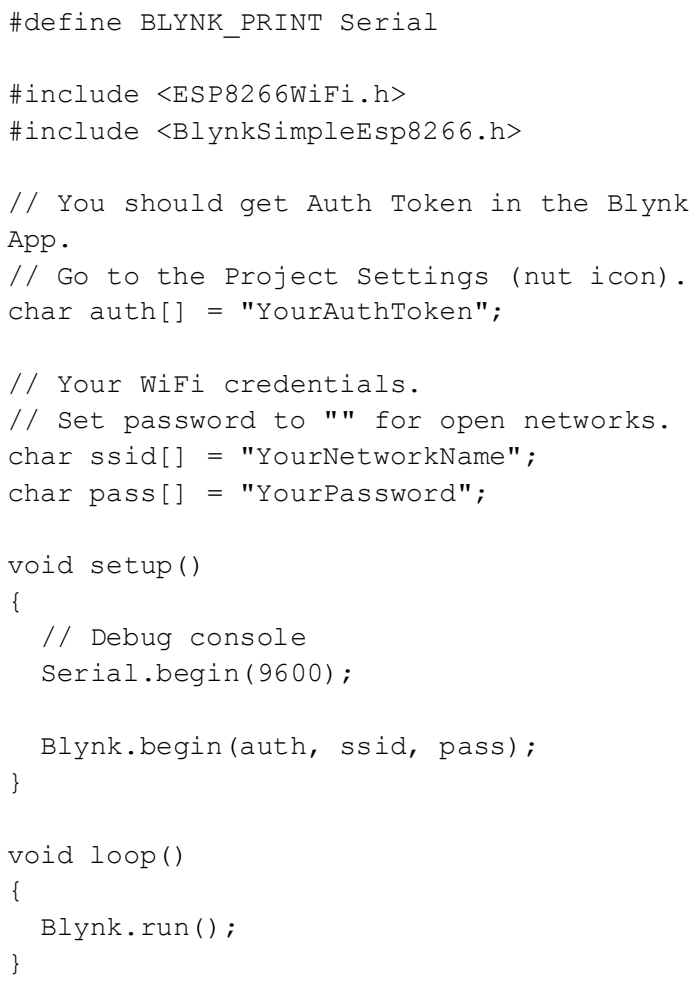

\section{RESULTS}

In order to see how the device works, an android phone signed in using the same google account as the IFTTT We have to use android phone that signed in with the same google account as in the IFTTT website.

Saying "Turn on the lamp" will trigger the Webhooks to set the pin value to " 1 " that will trigger the relay and turn the lamp on as can be seen in Figure 8.

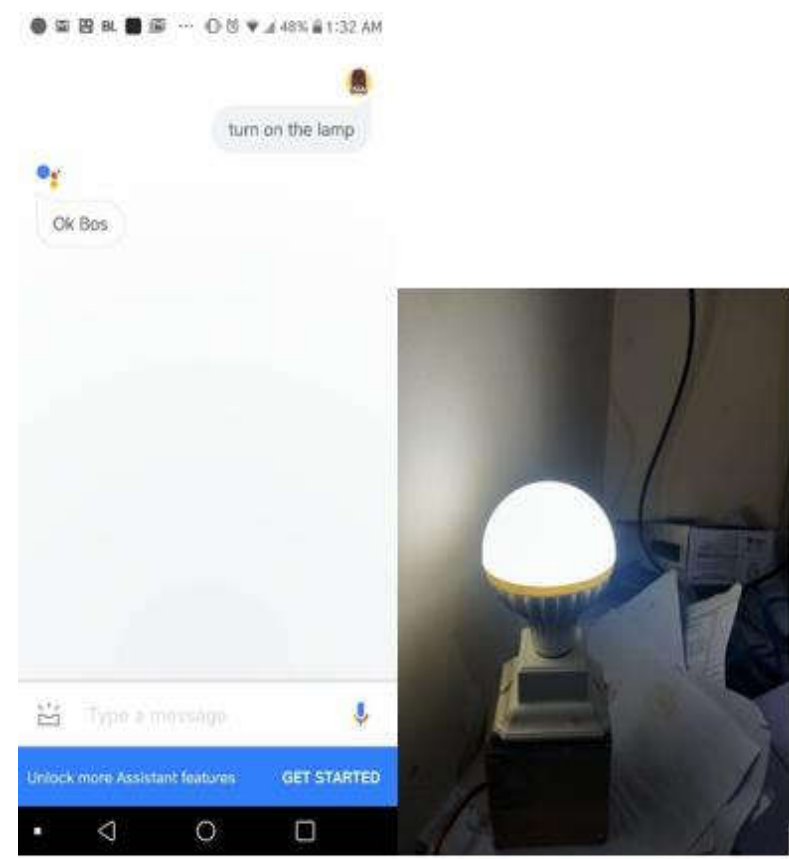

Figure 8. Device Testing (turning on the lamp).

Similarly, to turn off the lamp, one can say, "Turn off the lamp" and the Webhooks will trigger the relay to turn off the lamp as shown in Figure 9.

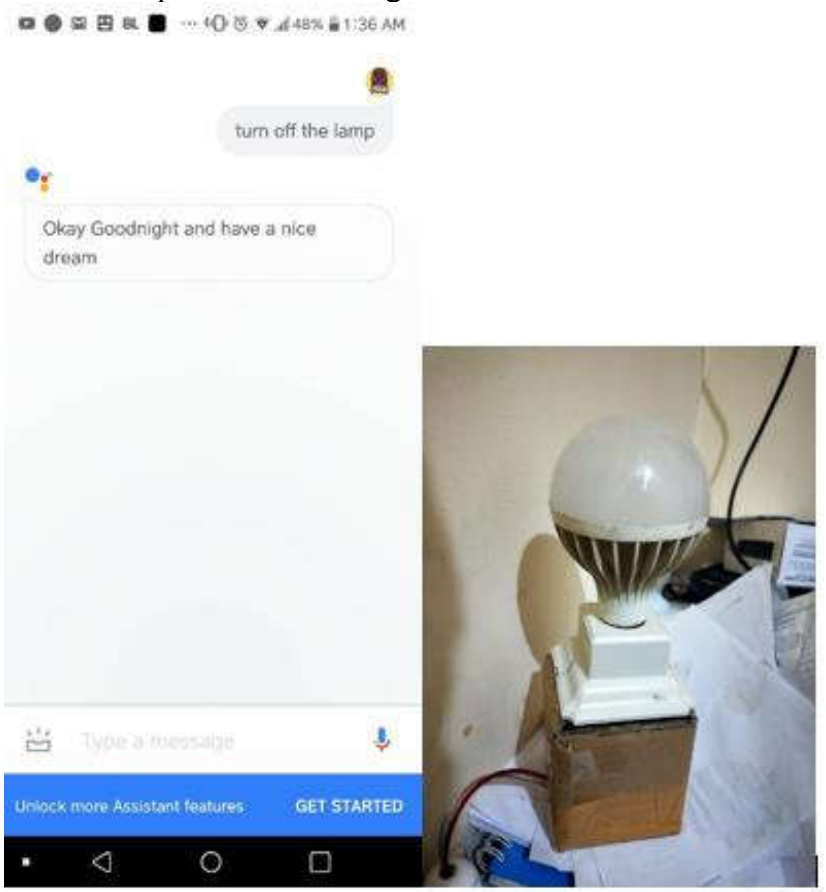

Figure 9. Device Testing (turning off the lamp). 


\section{CONCLUSION}

The innovation of IoT is very huge right now, it is spreading to many sectors such as sports, industry, home, etc. These are affected by the human needs, but time by time technology and environment force us to make any innovation that effective and useful. So basically, this project is very important for our life, within this benefit actually so many things we can do easily.

Example, smart lamp is great innovation that actually can help many people, to simplify our work. Besides so many benefits given, the manufacture of the smart lamp is very easy that maybe everyone can install. Within any further, we can customize as we need that maybe in the next progress the use of it will help more people.

\section{REFERENCES}

[1] Nodemcu,

2017 ,

[online]

Available: http://www.nodemcu.com/. (Accessed: 10th December 2017).

[2] A. Adriansyah, A.W. Dani, "Design of Small Smart Home Control Systems Based on Wireless Sensor Networks and Power Line Communications", IEEE, 2014.

[3] K. Baraka, et.al., "Low cost Arduino/Android-based Energy-Efficient Home Automation System with Smart Task Scheduling", Fifth International Conference on Computational Intelligence, 2013.

[4] C.F. et al., "The Internet of Things", First International Conference, 2008.

[5] D. Zeng, S. Guo, Z. Cheng, "The Web of Things: A Survey", Journal of Communications, 2011. 